\title{
Assessing the Effect of Temporal Interval Length on the Blending of Landsat-MODIS Surface Reflectance for Different Land Cover Types in Southwestern Continental United States
}

\section{Dongjie Fu ${ }^{1}$, Lifu Zhang ${ }^{1, *}$, Hao Chen ${ }^{1}$, Juan Wang ${ }^{2}$, Xuejian Sun ${ }^{1}$ and Taixia Wu ${ }^{1}$}

1 State Key Laboratory of Remote Sensing Science, Institute of Remote Sensing and Digital Earth, Chinese Academy of Sciences, Beijing 100101, China; E-Mails: fudongjie@gmail.com (D.F.); chenhao91@radi.ac.cn (H.C.); sunxuejian1@163.com (X.S.); wutx@ radi.ac.cn (T.W.)

2 Urban Science Department, College of Applied Arts and Science of Beijing Union University, Beijing 100191, China; E-Mail: juaner1020@gmail.com

* Author to whom correspondence should be addressed; E-Mail: zhanglf@ radi.ac.cn;

Tel.: +86-010-648-39450; Fax: +86-010-648-39450.

Academic Editor: Wolfgang Kainz

Received: 18 September 2015 / Accepted: 9 November 2015 / Published: 17 November 2015

\begin{abstract}
Capturing spatial and temporal dynamics is a key issue for many remote-sensing based applications. Consequently, several image-blending algorithms that can simulate the surface reflectance with high spatial-temporal resolution have been developed recently. However, the performance of the algorithm against the effect of temporal interval length between the base and simulation dates has not been reported. In this study, our aim was to evaluate the effect of different temporal interval lengths on the accuracy using the widely used blending algorithm, Spatial and Temporal Adaptive Reflectance Fusion Model (STARFM), based on Landsat, Moderate-resolution Imaging Spectroradiometer (MODIS) images and National Land Cover Database (NLCD). Taking the southwestern continental United States as the study area, a series of experiments was conducted using two schemes, which were the assessment of STARFM with (i) a fixed base date and varied simulation date and (ii) varied base date and specific simulation date, respectively. The result showed that the coefficient of determination $\left(\mathrm{R}^{2}\right)$, Root Mean Squared Error (RMSE) varied, and overall trend of $\mathrm{R}^{2}$ decreased along with the increasing temporal interval between the base and simulation dates for six land cover types. The mean $\mathrm{R}^{2}$ value of cropland was lowest, whereas shrub had the highest value for two schemes. The result may facilitate selection of an
\end{abstract}


appropriate temporal interval when using STARFM.

Keywords: spatial-temporal image fusion; temporal interval; surface reflectance; Landsat; MODIS

\section{Introduction}

According to the fundamentals of satellite sensor design, a trade-off must be made among the spatial, temporal, and spectral resolutions. A single-sensor is constrained by the specific aim, which constitutes this sensor-specific data framework [1]; therefore, there is no single satellite sensor that can produce multispectral/hyperspectral images with both fine spatial and temporal resolution. To resolve this constraint, several spatial-temporal image fusion models have been developed to produce high spatial and temporal resolution reflectance, which has aroused great interest within the remote-sensing community [2]. The Spatial and Temporal Adaptive Reflectance Fusion Model (STARFM) was initially proposed, and has been documented to have the capacity of blending Landsat Thematic Mapper (TM)/Enhanced TM Plus (ETM+) images (30 m, 16-day) and Moderate-resolution Imaging Spectroradiometer (MODIS) images $(500 \mathrm{~m}$, daily) to simulate the daily surface reflectance at the Landsat spatial resolution and MODIS temporal frequency [3]. Subsequently, this model has been applied in many research fields, such as forest disturbance [4], evapotranspiration [5], net ecosystem exchange [6], gross primary production [7], land cover classification [8], phenology [9], leaf area index [10], and public health [11]. An enhanced STARFM, called ESTARFM [12], allowed overcoming some limitations of the original in heterogeneous landscape but was not superior in homogeneous regions with high temporal variance [1]. Meanwhile, several other improved and derived versions based on STARFM have subsequently been developed [4,13-15].

However, the spatial-temporal image fusion models have limitations when the simulation dates are distance from the available image pair at base date [16]. Until now, the temporal interval length between the base date and simulation date (hereafter referred to as $T_{b s}$ ) has been determined empirically using the available data when the spatial-temporal image fusion model has been used. No quantitative assessment of spatial-temporal image fusion model has been undertaken when the $T_{b s}$ is changed. Therefore, if we need to simulate surface reflectance with high spatial resolution, which does not exist on a specific date, the issue arises of how long $T_{b s}$ is suitable, with a predefined accuracy, using spatial-temporal image fusion. To our knowledge, there is no published literature evaluating the performance of spatial-temporal image fusion against the effect of $T_{b s}$.

In this study, we assessed the performance of spatial-temporal image fusion with an increasing $T_{b s}$ and analyzed the accuracy with different $T_{b s}$ values for different land cover types. The STARFM was used with one-pair of Landsat-MODIS at a base date for the study. Combined with land cover data, the main objective of this study was to give a quantitative analysis on the performance of STARFM with (i) a fixed base date, varied simulation dates and (ii) varied base dates, a specific simulation date. 


\section{Data and Methods}

\subsection{Study Area}

The study area was located in the southwest of the continental United States with an area of $36 \times 30 \mathrm{~km}^{2}$ (Figure 1), which is for the Central Arizona-Phoenix Long-Term Ecological Research (CAP LTER) project [17]. The study area has a dry (mean annual precipitation of $180 \mathrm{~mm}$ ) and warm (mean summer temperature of $30.8{ }^{\circ} \mathrm{C}$ ) climate with two distinct wet seasons (one is in summer, the other is in winter). The native vegetation is dominated by two subdivisions of the Sonoran desert scrub: One is Arizona Upland subdivision with Paloverde-Mixed Cacti series (composed of Cercidium microphyllum, Olneya tesota, Simmondsia chinensis, Larrea tridentata, Encelia farinosa, Fouquieria splendens, Carnegiea gigantea and Opuntia sp.), the other is Lower Colorado River subdivision with Creosotebush-Bursage series (Larrea tridentata and Ambrosia dumosa) [18]. The other native riparian vegetation is characterized by riparian scrubland along minor drainages. The managed vegetation for the study area is mainly cropland [19]. The land cover types in this region include cropland, grassland, shrub, urban, water, and wetland, which were reclassified from the eight broad classes based on National Land Cover Database (NLCD) classification system [20-22]. Specifically, cropland type includes cultivated crops; grassland type includes grassland/herbaceous and pasture/hay; shrub type includes dwarf scrub and shrub/scrub; urban type includes (i) developed, open space, (ii) developed, low intensity, (iii) developed, medium intensity, and (iv) developed high intensity; water type includes open water and perennial ice/snow; and wetland type includes woody wetlands and emergent herbaceous wetlands. The other land cover types comprised less than $0.1 \%$ of the study area, consequently, they were not taken into account in this study. More than half of the cropland and wetland has two growing seasons, while grassland and shrub has one growing season per year [23]. The peak of growth for shrub, wetland is in early spring, early summer to early autumn, respectively. Cropland has the shortest growth length and fastest green-up rate. Grassland has the longest growth length, which never drops below a certain value. Shrub growth starts from early August or November, and ends in early summer. Wetland, with two growing seasons, green up in mid-February and defoliate in July. The date of beginning and end growth for cropland are closer to wetland than shrub [23].

\subsection{Data}

The datasets used in this study were as follows: (i) Landsat TM/ETM+ surface reflectance (2001-2012), (ii) MODIS reflectance (2001-2012) and (iii) land cover data (2001, 2006 and 2011).

The Landsat TM/ETM+ surface reflectance product (path/row: 037/037) covering the study area was acquired form EarthExplorer of United States Geological Survey (USGS) (http://earthexplorer.usgs.gov/) during the period 2001 to 2012. Only Landsat surface reflectance data with overall cloud cover of less than $20 \%$ were selected as candidates, which can cover the most of the Landsat data within the extent of study area without cloud contaminated. Candidate data were then clipped to the extent of the study area $\left(36 \times 30 \mathrm{~km}^{2}\right)$, and the clipped data with cloud cover of more than $15 \%$ were not used based on the corresponding cfmask band. A total of 299 scenes of Landsat data were finally used (TM: 142, ETM+: 157), and information of frequency and day of year (DOY) distribution is shown in Figure 2. The gap 
within Landsat 7 ETM+ Scan Line Corrector (SLC)-off data was not taken into account for the performance assessment of spatial-temporal image fusion.

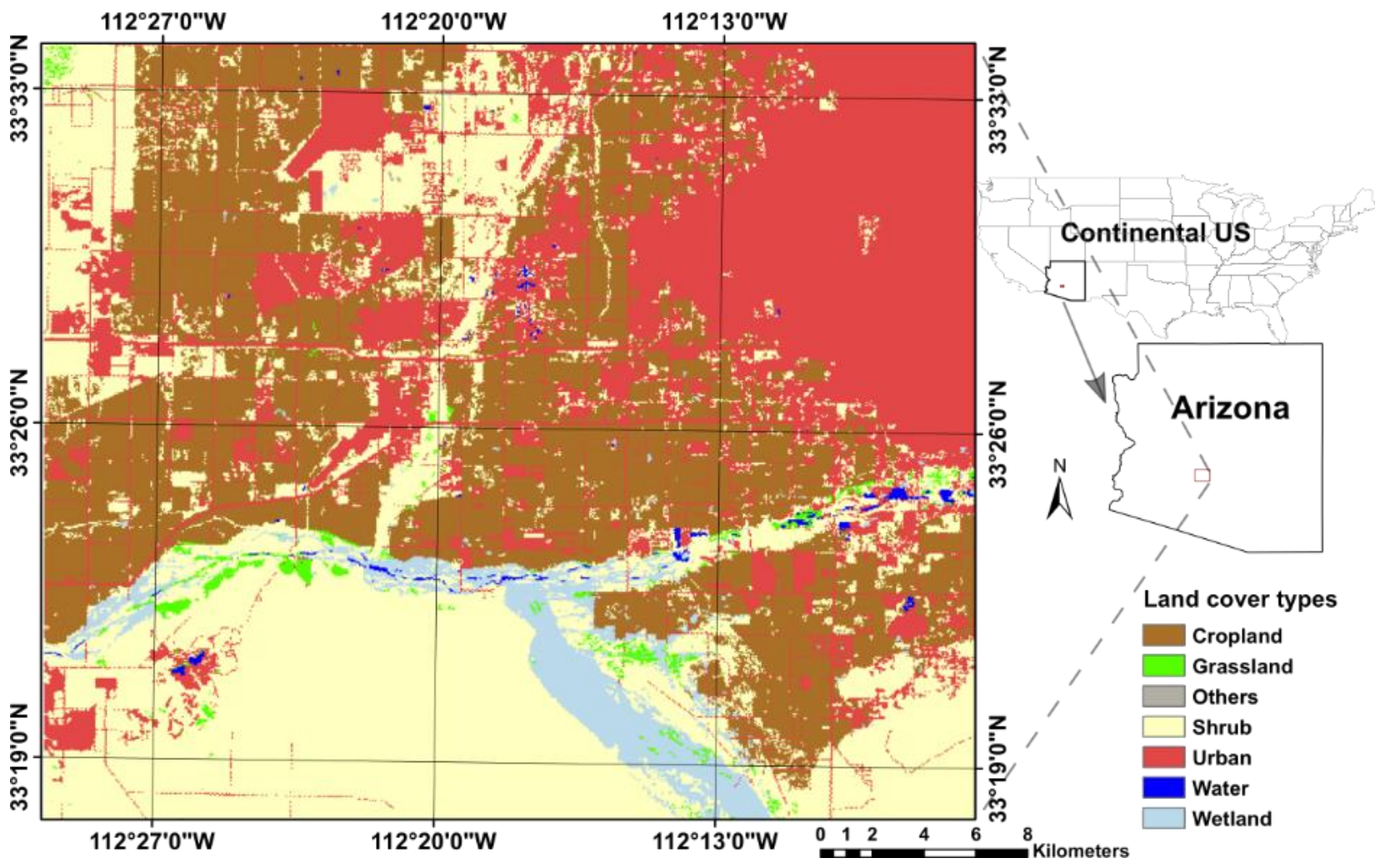

Figure 1. Land cover map (National Land Cover Database (NLCD), year: 2001) of the study area.
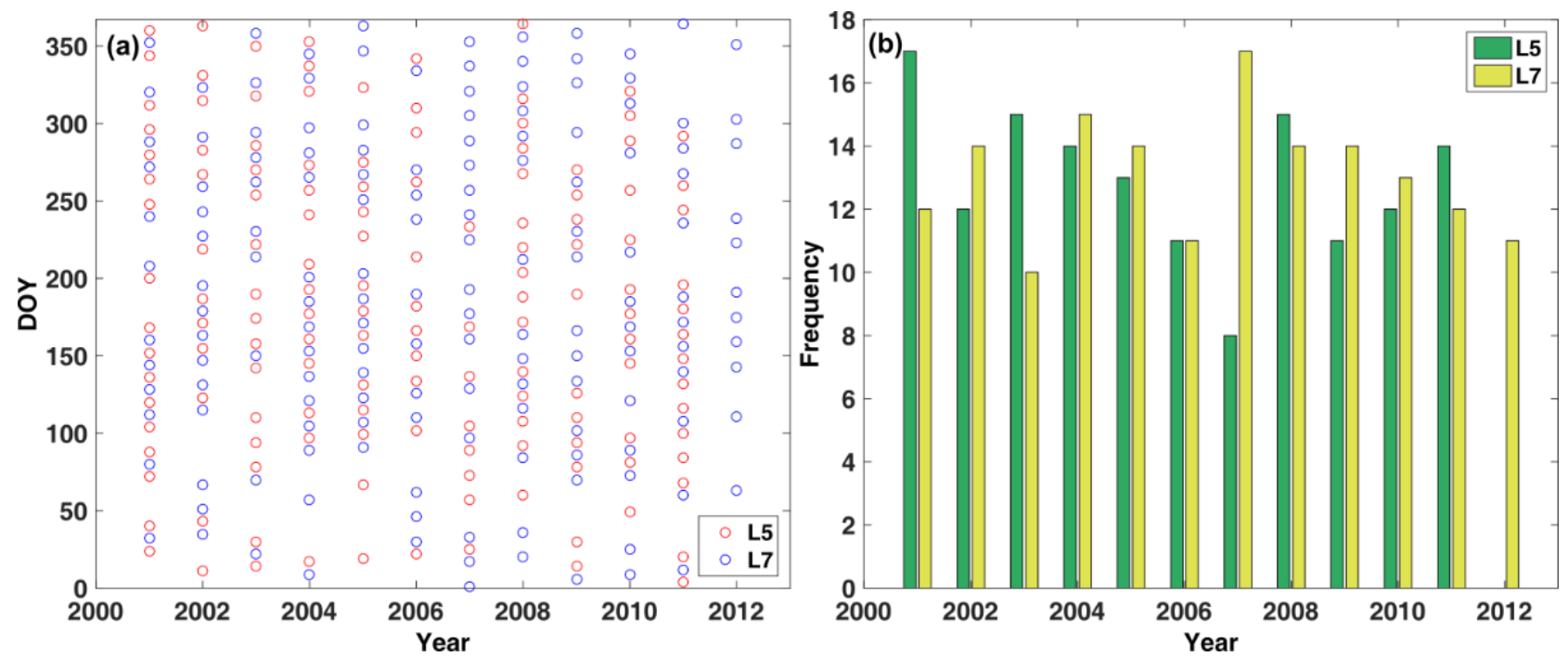

Figure 2. Distribution of the Landsat data used in the study. (a) day of year (DOY), (b) frequency from the period 2001 to 2012. L5 denotes Landsat TM data, L7 denotes Landsat ETM+ data.

For MODIS data, MOD09A1 product data (8-day reflectance, $500 \mathrm{~m}$, Collection 5, tile: h08v05) for the study area were obtained from the National Aeronautics and Space Administration (NASA) Earthdata portal 
(https://search.earthdata.nasa.gov/) for the period 2001 to 2012. The MODIS data were re-projected, resampled and clipped to the same spatial extent $\left(36 \times 30 \mathrm{~km}^{2}\right)$ and resolution as the Landsat projection using the MODIS Reprojection Tool (MRT) (available at URL https://lpdaac.usgs.gov/tools/ modis_reprojection_tool). Any invalid MOD09A1 data were eliminated using the quality assurance (QA) layer included in the product [6].

For land cover data, NLCD with a spatial resolution of $30 \mathrm{~m}$ were obtained from the Multi-Resolution Land Characteristics Consortium (MRLC) (http://www.mrlc.gov/index.php) for the years 2001, 2006, and 2011. We assumed that the status of the study area during 2001-2003 could be represented by NLCD 2001; the status of study area during 2004-2008 could be represented by NLCD 2006; and the status of study area during 2009-2012 could be represented by NLCD 2011. Nationally, the overall accuracy of NLCD 2001, and 2006 is 79\% and 78\%, respectively [24]. For NLCD 2011, the accuracy assessment is currently underway [25].

\subsection{STARFM}

STARFM, which was developed by Gao, Masek, Schwaller and Hall [3], was used in the study. Only one pair of Landsat and MODIS images acquired on the base date and one MODIS observation on the simulation date were taken into account.

Landsat-like surface reflectance was obtained on the simulation date using the following steps. First, the spectral similar neighboring pixels within a local moving window of Landsat data were identified. Second, a weight $W_{i j k}$ was calculated for each spectral similar neighboring pixel based on: (i) the spectral difference between the Landsat and MODIS data on the base date, (ii) the temporal difference of the MODIS data between the base and simulation date, and (iii) the spatial Euclidean distance between the neighbor and the central pixel within the local moving window. Finally, the surface reflectance of the central pixel was calculated as follows:

$$
L\left(x_{w / 2}, y_{w / 2}, t_{s}\right)=\sum_{i=1}^{w} \sum_{j=1}^{w} \sum_{b=1}^{n} W_{i j k} \times\left(M\left(x_{i}, y_{j}, t_{s}\right)+L\left(x_{i}, y_{j}, t_{b}\right)-M\left(x_{i}, y_{j}, t_{b}\right)\right)
$$

where $L$ and $M$ indicate the surface reflectance of Landsat and MODIS, respectively; $L\left(x_{w / 2}, y_{w / 2}, t_{s}\right)$ is the surface reflectance of the central pixel $\left(x_{w / 2}, y_{w / 2}\right)$ on the simulation date $t_{s}$ for Landsat; $M\left(x_{i}, y_{j}, t_{b}\right)$ is the surface reflectance of pixel $\left(x_{i}, y_{j}\right)$ within local moving window on the base date $\left(t_{b}\right)$ for MODIS; and $w$ is the size of the local moving window. For more detailed information of STARFM, see Gao, Masek, Schwaller and Hall [3].

\subsection{Evaluation with a Fixed Base Date}

To evaluate the performance of STARFM with a fixed base date, we changed the value of $T_{b s}$. Specifically, one date was selected as the base date for every month of 2001, 2003 and 2008. For each month, only the Landsat data with the lowest cloud cover percentage were selected as the base data, and the corresponding date was defined as base date (Table 1). The number of base dates in 2008 was 20, which is more than 12. When evaluating the performance of STARFM with each fixed base date, the value of $T_{b s}$ increased until it reached the last simulation date in 2012. 
Four pairs of Landsat-MODIS data on the base dates of 9 February, 16 May, 28 August, and 8 November 2001, were selected. Land cover data from the NLCD for 2001, 2006, and 2011 were used to assess the performance of STARFM on a fixed base date. Based on four fixed base dates (9 February, 16 May, 28 August, and 8 November 2001), the performance of STARFM was evaluated according to six land cover types. We defined four seasons and the corresponding months as winter (December, January and February), spring (March, April and May), summer (June, July and August), and autumn (September, October and November). We assumed that each Landsat-MODIS pair on the base date represented the average status of the study areas in the corresponding season.

Table 1. Details of the base date for the spatial-temporal image fusion. Abbreviations: January (Jan.), February (Feb.), March (Mar.), April (Apr.), June (Jun.), July (Jul.), August (Aug.), September (Sep.), October (Oct.), November (Nov.), December (Dec.). For column of Sensor, L5 denotes Landsat TM, and L7 denotes Landsat ETM+. *The base date for February 2003 is 30 January 2003, because no Landsat data is available in February 2003 and the Landsat data on 30 January 2003 is the closest one to February 2003.

\begin{tabular}{|c|c|c|c|c|c|c|c|c|c|c|c|c|}
\hline \multirow{3}{*}{ Year } & \multirow{3}{*}{ Month } & \multirow{3}{*}{ Day } & \multirow{3}{*}{ DOY } & \multirow{3}{*}{ Sensor } & \multicolumn{8}{|c|}{ Day since Start of the Dataset } \\
\hline & & & & & \multicolumn{4}{|c|}{ Fixed Base Date (2001) } & \multicolumn{4}{|c|}{ Specific Simulation Date (2009) } \\
\hline & & & & & $\begin{array}{c}\text { Feb. } \\
9 \\
\end{array}$ & May 16 & $\begin{array}{c}\text { Aug. } \\
28 \\
\end{array}$ & Nov. 8 & $\begin{array}{c}\text { Jan. } \\
14 \\
\end{array}$ & $\begin{array}{c}\text { Apr. } \\
12 \\
\end{array}$ & $\begin{array}{c}\text { Jul. } \\
9 \\
\end{array}$ & $\begin{array}{c}\text { Oct. } \\
21\end{array}$ \\
\hline \multirow[t]{12}{*}{2001} & Jan. & 24 & 24 & L5 & - & - & - & - & 2912 & 3000 & 3088 & 3192 \\
\hline & Feb. & 9 & 40 & L5 & - & - & - & - & 2896 & 2984 & 3072 & 3176 \\
\hline & Mar. & 13 & 72 & L5 & 32 & - & - & - & 2864 & 2952 & 3040 & 3144 \\
\hline & Apr. & 14 & 104 & L5 & 64 & - & - & - & 2832 & 2920 & 3008 & 3112 \\
\hline & May & 16 & 136 & L5 & 96 & - & - & - & 2800 & 2888 & 2976 & 3080 \\
\hline & Jun. & 17 & 168 & L5 & 128 & 32 & - & - & 2768 & 2856 & 2944 & 3048 \\
\hline & Jul. & 19 & 200 & L5 & 160 & 64 & - & - & 2736 & 2824 & 2912 & 3016 \\
\hline & Aug. & 28 & 240 & L7 & 200 & 104 & - & - & 2696 & 2784 & 2872 & 2976 \\
\hline & Sep. & 21 & 264 & L5 & 224 & 128 & 24 & - & 2672 & 2760 & 2848 & 2952 \\
\hline & Oct. & 23 & 296 & L5 & 256 & 160 & 56 & - & 2640 & 2728 & 2816 & 2920 \\
\hline & Nov. & 8 & 312 & L5 & 272 & 176 & 72 & - & 2624 & 2712 & 2800 & 2904 \\
\hline & Dec. & 18 & 352 & L7 & 312 & 216 & 112 & 40 & 2584 & 2672 & 2760 & 2864 \\
\hline \multirow[t]{12}{*}{2003} & Jan. & 14 & 14 & L5 & 704 & 608 & 504 & 432 & 2192 & 2280 & 2368 & 2472 \\
\hline & Feb. & $30^{*}$ & 30 & L5 & 720 & 624 & 520 & 448 & 2176 & 2264 & 2352 & 2456 \\
\hline & Mar. & 11 & 70 & L7 & 760 & 664 & 560 & 488 & 2136 & 2224 & 2312 & 2416 \\
\hline & Apr. & 20 & 110 & L5 & 800 & 704 & 600 & 528 & 2096 & 2184 & 2272 & 2376 \\
\hline & May & 22 & 142 & L5 & 832 & 736 & 632 & 560 & 2064 & 2152 & 2240 & 2344 \\
\hline & Jun. & 23 & 174 & L5 & 864 & 768 & 664 & 592 & 2032 & 2120 & 2208 & 2312 \\
\hline & Jul. & 9 & 190 & L5 & 880 & 784 & 680 & 608 & 2016 & 2104 & 2192 & 2296 \\
\hline & Aug. & 10 & 222 & L5 & 912 & 816 & 712 & 640 & 1984 & 2072 & 2160 & 2264 \\
\hline & Sep. & 11 & 254 & L5 & 944 & 848 & 744 & 672 & 1952 & 2040 & 2128 & 2232 \\
\hline & Oct. & 13 & 286 & L5 & 976 & 880 & 776 & 704 & 1920 & 2008 & 2096 & 2200 \\
\hline & Nov. & 14 & 318 & L5 & 1008 & 912 & 808 & 736 & 1888 & 1976 & 2064 & 2168 \\
\hline & Dec. & 16 & 350 & L5 & 1040 & 944 & 840 & 768 & 1856 & 1944 & 2032 & 2136 \\
\hline
\end{tabular}


Table 1. Cont.

\begin{tabular}{|c|c|c|c|c|c|c|c|c|c|c|c|c|}
\hline \multirow{3}{*}{ Year } & \multirow{3}{*}{ Mon } & \multirow{3}{*}{ Day } & \multirow{3}{*}{$\begin{array}{c}\text { DO } \\
\mathbf{Y}\end{array}$} & \multirow{3}{*}{ Sensor } & \multicolumn{8}{|c|}{ Day since Start of the Dataset } \\
\hline & & & & & \multicolumn{4}{|c|}{ Fixed Base Date (2001) } & \multicolumn{4}{|c|}{ Specific Simulation Date (2009) } \\
\hline & & & & & Feb. 9 & May 16 & Aug. 28 & Nov. 8 & Jan. 14 & Apr. 12 & Jul. 9 & Oct. 21 \\
\hline \multirow[t]{8}{*}{2008} & Jan. & 20 & 20 & L7 & 2536 & 2440 & 2336 & 2264 & 360 & 448 & 536 & 640 \\
\hline & Feb. & 5 & 36 & L7 & 2552 & 2456 & 2352 & 2280 & 344 & 432 & 520 & 624 \\
\hline & & 29 & 60 & L5 & 2576 & 2480 & 2376 & 2304 & 320 & 408 & 496 & 600 \\
\hline & Mar. & 24 & 84 & L7 & 2600 & 2504 & 2400 & 2328 & 296 & 384 & 472 & 576 \\
\hline & Apr. & 17 & 108 & L5 & 2624 & 2528 & 2424 & 2352 & 272 & 360 & 448 & 552 \\
\hline & & 25 & 116 & L7 & 2632 & 2536 & 2432 & 2360 & 264 & 352 & 440 & 544 \\
\hline & May & 3 & 124 & L5 & 2640 & 2544 & 2440 & 2368 & 256 & 344 & 432 & 536 \\
\hline & & 11 & 132 & L7 & 2648 & 2552 & 2448 & 2376 & 248 & 336 & 424 & 528 \\
\hline \multirow[t]{12}{*}{2008} & Jun. & 12 & 164 & L7 & 2680 & 2584 & 2480 & 2408 & 216 & 304 & 392 & 496 \\
\hline & & 20 & 172 & L5 & 2688 & 2592 & 2488 & 2416 & 208 & 296 & 384 & 488 \\
\hline & Jul. & 22 & 204 & L5 & 2720 & 2624 & 2520 & 2448 & 176 & 264 & 352 & 456 \\
\hline & & 30 & 212 & L7 & 2728 & 2632 & 2528 & 2456 & 168 & 256 & 344 & 448 \\
\hline & Aug. & 23 & 236 & L5 & 2752 & 2656 & 2552 & 2480 & 144 & 232 & 320 & 424 \\
\hline & Sep. & 24 & 268 & L5 & 2784 & 2688 & 2584 & 2512 & 112 & 200 & 288 & 392 \\
\hline & Oct. & 10 & 284 & L5 & 2800 & 2704 & 2600 & 2528 & 96 & 184 & 272 & 376 \\
\hline & & 18 & 292 & L7 & 2808 & 2712 & 2608 & 2536 & 88 & 176 & 264 & 368 \\
\hline & Nov. & 3 & 308 & L7 & 2824 & 2728 & 2624 & 2552 & 72 & 160 & 248 & 352 \\
\hline & & 11 & 316 & L5 & 2832 & 2736 & 2632 & 2560 & 64 & 152 & 240 & 344 \\
\hline & Dec. & 5 & 340 & L7 & 2856 & 2760 & 2656 & 2584 & 40 & 128 & 216 & 320 \\
\hline & & 29 & 364 & L5 & 2880 & 2784 & 2680 & 2608 & 16 & 104 & 192 & 296 \\
\hline
\end{tabular}

\subsection{Evaluation for a Specific Simulation Date}

To evaluate the performance of STARFM on a specific simulation date, the value of $T_{b s}$ was increased until the farthest based date was reached. Specifically, four simulation dates in 2009 were selected for the study: 14 January, 12 April, 9 July, and 21 October 2009. Therefore, for each simulation date, 40 base date Landsat-MODIS pairs were used to produce 40 simulations (2001, 2003, and 2008) (Table 1). The land cover data from NLCD for 2001, 2006, and 2011 were also used to assess the performance of STARFM on specific simulation dates. We assumed that each simulated reflectance at the simulation date represented the average status of the study areas in the corresponding season.

\subsection{Accuracy Assessment}

We assessed the accuracy of simulations by comparing the simulated Landsat-like data to a Landsat observation on the same date. A linear regression model (observed versus simulated surface reflectance) was used to assess the performance of STARFM, with reference to the statistical parameter, $\mathrm{R}^{2}$ and Root Mean Squared Error (RMSE), which were used to measure the fitness of the linear regression, differences between simulated and observed reflectance, respectively. 


\section{Results}

\subsection{Landsat-Like Surface Reflectance with a Fixed Base Date}

The $\mathrm{R}^{2}$ and RMSE value varied seasonally, and $\mathrm{R}^{2}$ value was generally decreased as the value of the temporal interval between the base and simulation dates $\left(T_{b s}\right)$ increased. The RMSE value for band 1 is lowest compared to other bands. Generally, the DOYs of simulation dates for best/worst performance (maximum $\mathrm{R}^{2}$ and minimum RMSE/ minimum $\mathrm{R}^{2}$ and maximum RMSE) at each simulation year were near to/far from the DOY of base date (Figures 3 and 4).

(a)

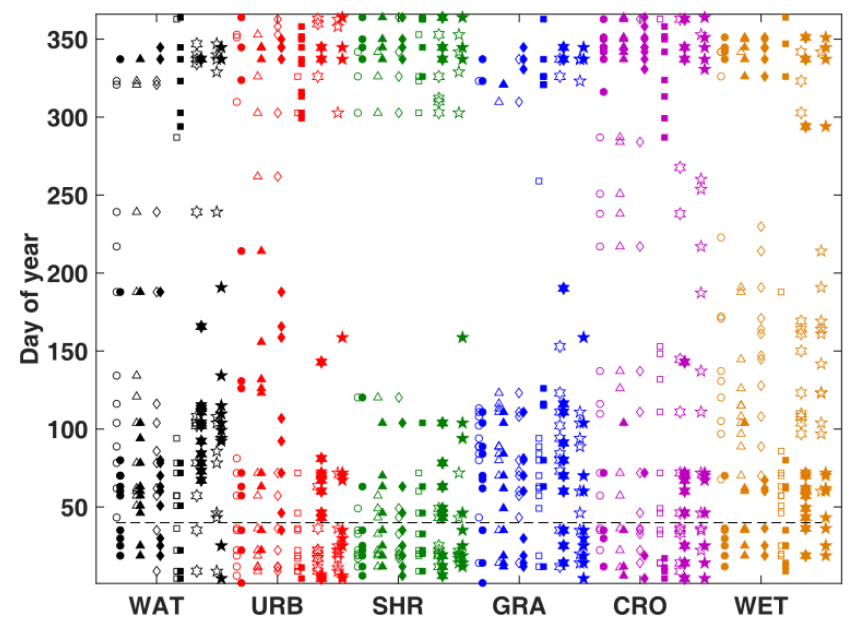

(c)

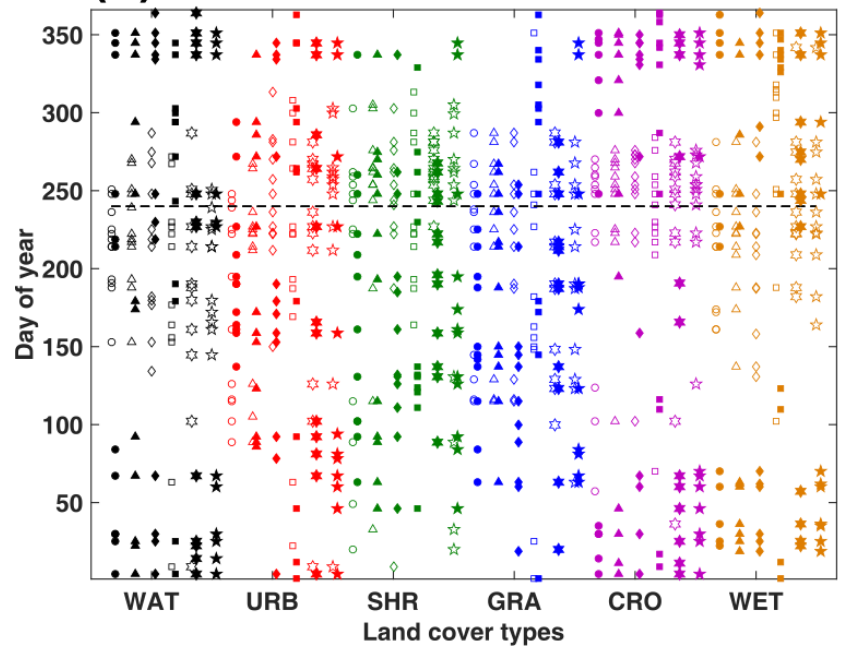

(b)

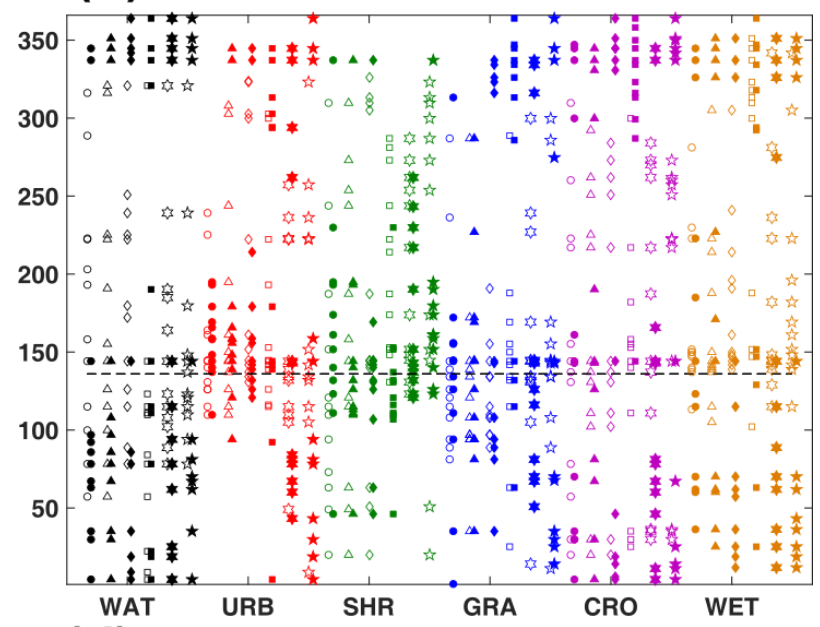

(d)

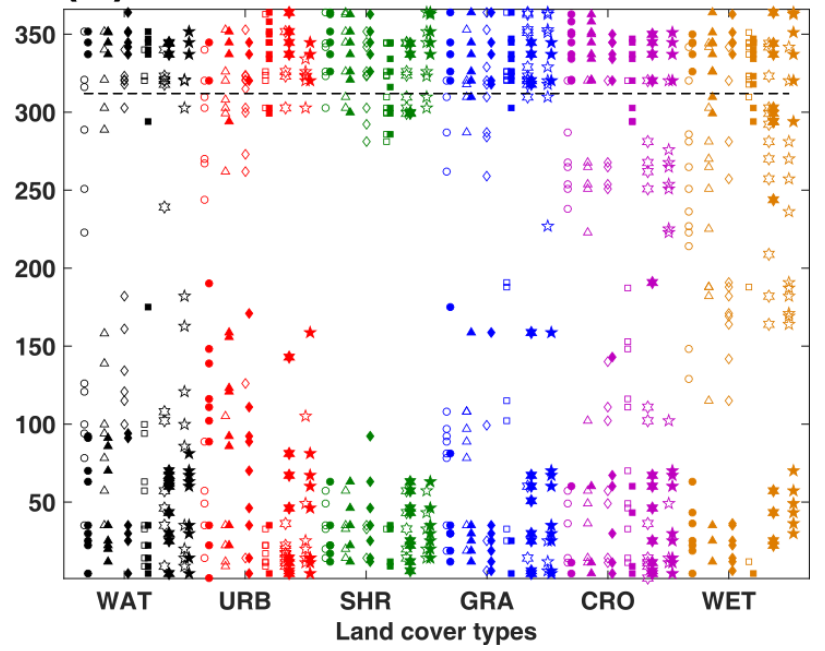

Figure 3. Distribution of the day of year (DOY) for maximum $\mathrm{R}^{2}$ (not filled marker) and minimum RMSE (filled marker) value at each year from 2001 to 2012. The corresponding base date (dash line) is (a) 9 February (DOY: 40), (b) 16 May (DOY: 136), (c) 28 August (DOY: 240) and (d) 8 November (DOY: 312) for year 2001, respectively. The markers for six Landsat-like bands are circle, triangle, diamond, square, hexagram and pentagram, respectively. The color for each land cover type is black (WAT: water), red (URB: urban), green (SHR: shrub), blue (GRA, grassland), violet (CRO: cropland) and brown (WET: wetland). The meaning of marker and color for symbols is the same for Figure 4. 
Specifically, with one pair of Landsat-MODIS images as base data on 9 February 2001 (DOY: 40), the high $\mathrm{R}^{2}$ and low RMSE values often occurred at the beginning (base date \pm 39 days) or end (last month) of the year (Figure 3a). The DOY of simulated reflectance with low $\mathrm{R}^{2}$ and high RMSE value at each year was mainly distributed from 140 to 300 (Figure 4a). When the temporal distance was within \pm 70 days between simulation date and base date, the high $\mathrm{R}^{2}$ and low RMSE value for water and grass can also be obtained. Among each land cover type, the performance of STARFM was worst for cropland, which median and mean $\mathrm{R}^{2}$ values for the six bands were lower than 0.25 , the RMSE value for band 4 had reached to 0.08 (Figures S1a, S2a, and S3a). The best performance of STARFM was simulated result for shrub, the median and mean $\mathrm{R}^{2}$ values for each Landsat band was higher than any other land cover type, the simulated reflectance of band 5 was closer $\left(\mathrm{R}^{2}\right)$ to the observed reflectance than to the other bands, and result of band 1 had lowest bias compared to other bands (Figures S1c, S2c, and S3c).

(a)

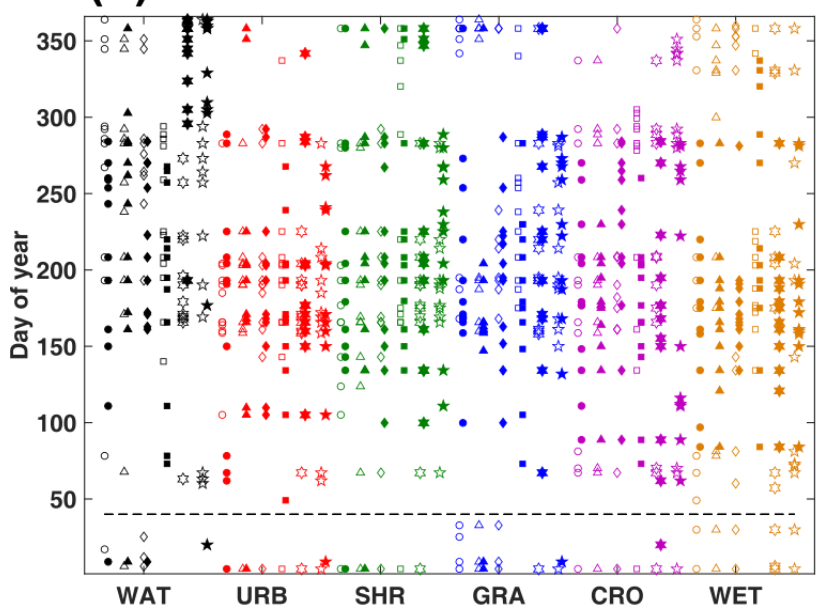

(c)

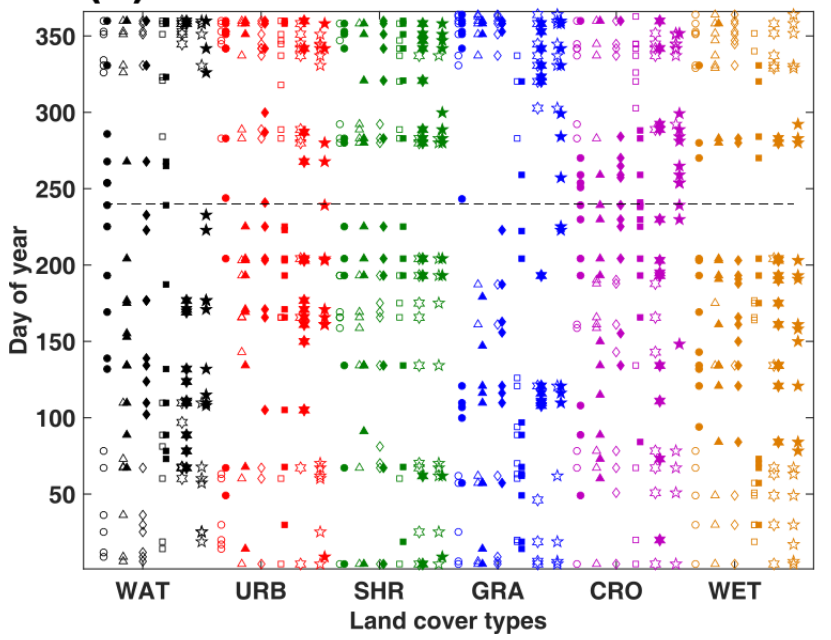

(b)

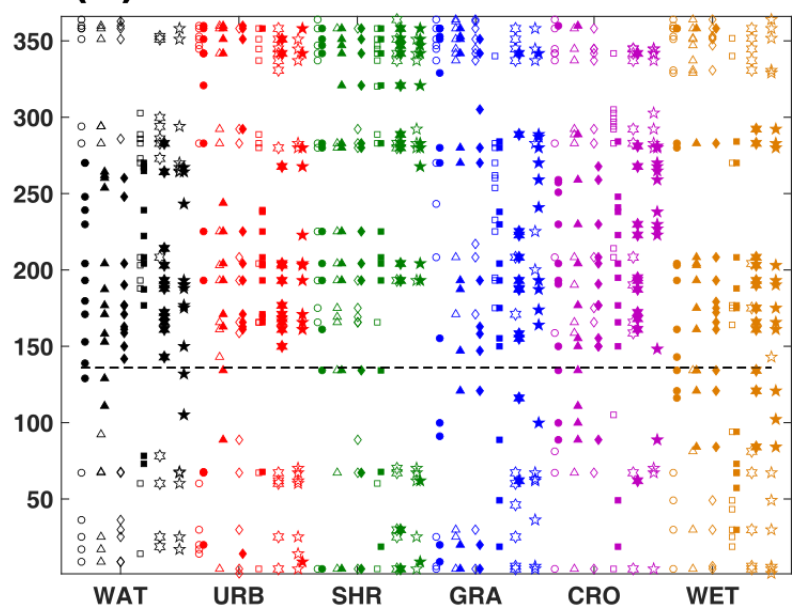

(d)

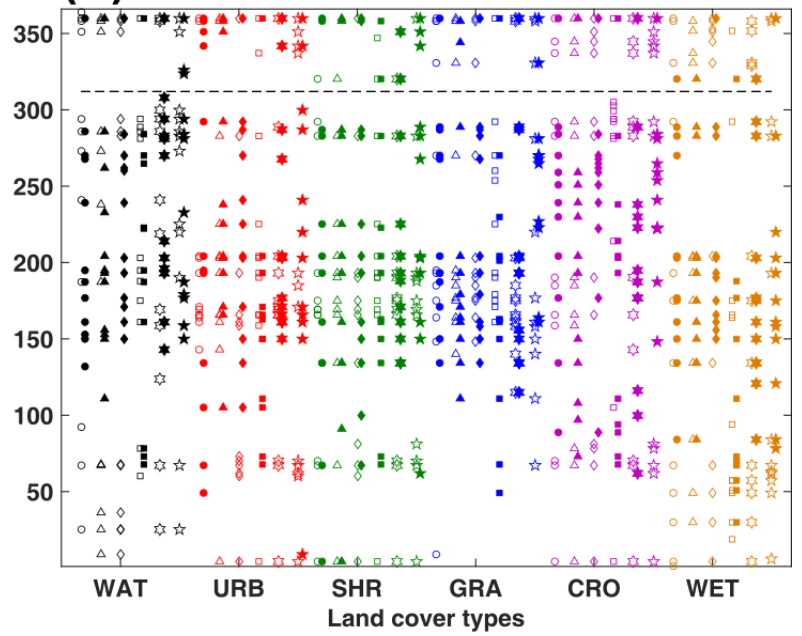

Figure 4. Distribution of the day of year (DOY) for minimum $\mathrm{R}^{2}$ (not filled marker) and maximum RMSE (filled marker) value at each year from 2001 to 2012. The corresponding base date (dash line) is (a) 9 February (DOY: 40), (b) 16 May (DOY: 136), (c) 28 August (DOY: 240) and (d) 8 November (DOY: 312) for year 2001, respectively.

When the base date was moved to 16 May 2001 (DOY: 136), the highest $\mathrm{R}^{2}$ and low RMSE often occurred in the middle (base date \pm 30 days) of the year for most land cover types. However, the high 
$\mathrm{R}^{2}$ and low RMSE value can also been obtained when the simulation DOY was extended to the beginning of the year for water, cropland, wetland and the band 5 and 7 of urban (Figure 3b). The DOY of simulated reflectance with low $\mathrm{R}^{2}$ and high RMSE value at each year was mainly distributed at two extents (150-300 and 340-365) (Figure 4b). The simulated reflectance of shrub still had high $\mathrm{R}^{2}$ and low RMSE value (Figures S4c, S5c, and S6c). For cropland, the situation is reversed (Figures S4a, S5a, and S6a). For urban areas, the $\mathrm{R}^{2}$ value had two significant declines, one from 2003 to 2004, and the other from 2008 to 2009 . The upper $25 \%$ of data are quite sparse in comparison with the lower $25 \%$ for urban land cover type, the RMSE value had a slight increase from year 2003 to 2004 (Figures S4d, S5d, and S6d).

For base date of 28 August 2001 (DOY: 240), the distribution of DOY for simulated reflectance with high $\mathrm{R}^{2}$ and low RMSE value at each year was different compared to previous two base dates. The extent of DOY with high $\mathrm{R}^{2}$ (base date \pm 40 days) was different from low RMSE value for water, urban, cropland and wetland (Figure 3c). The high RMSE for water, urban and cropland can be found near the base date (Figure $4 \mathrm{c}$ ). The $\mathrm{R}^{2}$ value near the base date was higher than other three base dates. Specifically, for cropland, the $\mathrm{R}^{2}$ value was 0.7 or higher, with the exception of band 4 . An obvious seasonal variation was also apparent (Figures S7a and S8a). For grassland, the $\mathrm{R}^{2}$ value was 0.9 or even higher for each band. The trend was similar to the results of the other three base date (Figures S7b, S8b, and S9b). For shrub, the simulated reflectance was closer to the observed reflectance, with $\mathrm{R}^{2}$ values higher than 0.9 and almost RMSE values lower than 0.04 (Figures S7c, S8c, and S9c). For other land cover types, the trends of the $\mathrm{R}^{2}$ value were similar to that of the $\mathrm{R}^{2}$ value for the base date of 16 May 2001, but there was a higher $\mathrm{R}^{2}$ value for the base date 28 August 2001 (Figures S7d,e,f, S8d,e,f, and S9d,e,f).

For the base date of 8 November 2001 (DOY: 312), the DOY for high $\mathrm{R}^{2}$ and low RMSE often distributed at the end (300-365) or beginning (1-60) of the year (Figure $3 \mathrm{~d}$ ). The $\mathrm{R}^{2}$ of cropland was satisfactory at the beginning of the simulation date, and was 0.8 or higher for bands 2 and 3 . The corresponding RMSE value is lower than 0.04. The simulated reflectance for band 4 still held the lowest median $\mathrm{R}^{2}$ value $(<0.1)$ (Figures S10a, S11a, and S12a). For the other five land cover types, the trend in the $\mathrm{R}^{2}$ and RMSE value was similar to that for the $\mathrm{R}^{2}$ and RMSE value for the base date of 9 February 2001, but with higher $\mathrm{R}^{2}$ value for the base date of 8 November 2001 (Figures S10, S11, and S12).

\subsection{Landsat-Like Surface Reflectance on A Specific Simulation Date}

Similarly, the DOYs of base dates for best/worst performance (maximum $\mathrm{R}^{2}$ and minimum RMSE/ minimum $\mathrm{R}^{2}$ and maximum RMSE) at each base year were near to/far from the DOY of simulation date (Figures 5 and 6). When the simulation date was 14 January 2009 (DOY: 14), the $\mathrm{R}^{2}$ and RMSE value varied as the $T_{b s}$ increased, and the overall trend of $\mathrm{R}^{2}$ become more apparent. The high $\mathrm{R}^{2}$ and low RMSE value often occurred at the beginning and end of the year (Figure 5a), and the $\mathrm{R}^{2}$ value at the end was higher than at the beginning of the year 2008 for six land cover types (Figures S13 and S14). The low $\mathrm{R}^{2}$ and high RMSE value mainly distributed at the middle of the year (DOY: 60-210) (Figure 6a). For cropland, the $\mathrm{R}^{2}$ values of the first three and last two bands exceeded 0.70 and 0.60 for the nearest two base dates (5 December and 29 December 2008), and the corresponding $T_{b s}$ was 40 and 16 days, respectively (Figure S13a). The corresponding magnitude of RMSE for cropland at year 2001, 2003 and 2008 were similar (Figure S14a). The patterns of $\mathrm{R}^{2}$ distributions for grassland and shrub were also similar, 
but the mean $\mathrm{R}^{2}$ value of shrub was higher than grassland (Figure $\mathrm{S} 13 \mathrm{~b}, \mathrm{c}$ ). The $\mathrm{R}^{2}$ value of urban for year 2008 was much higher than for years 2001 and 2003; this is also reflected in the lower RMSE value for year 2008 compared to other two years (Figures S13d and S14d). The trend of $R^{2}$ for water and wetland was similar, but the trend of RMSE was different (Figures S13e,f and S14e,f).

(a)

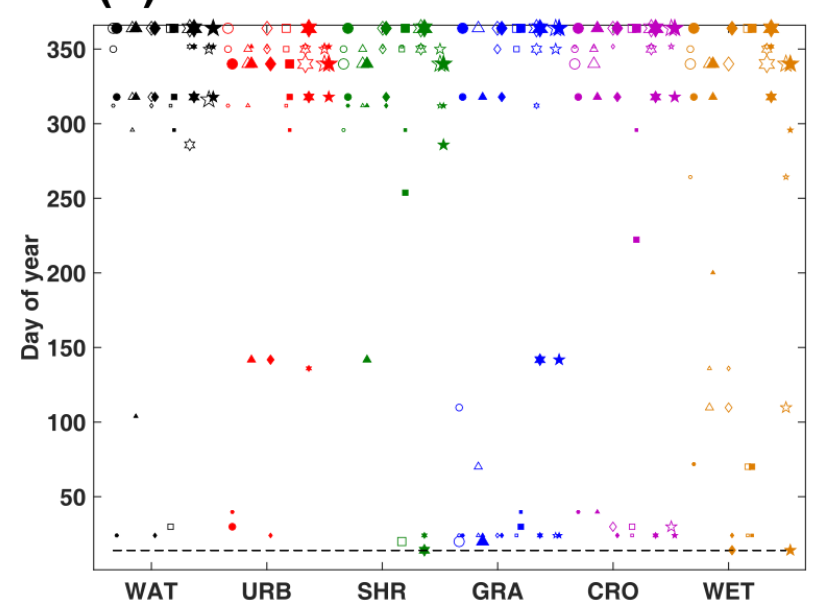

(c)

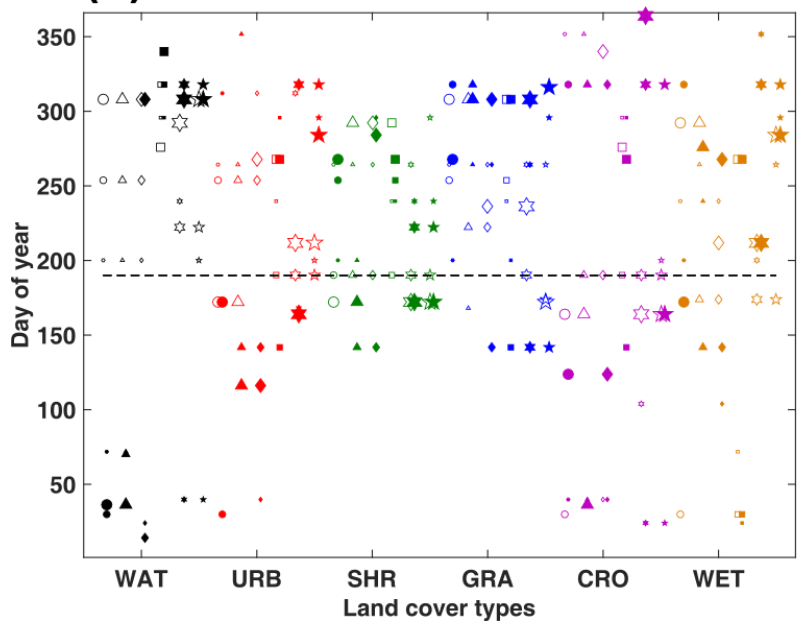

(b)

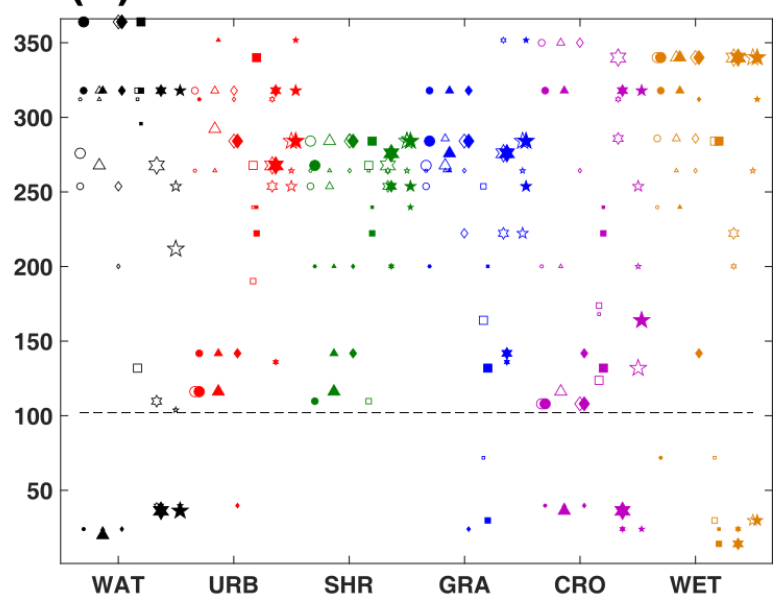

(d)

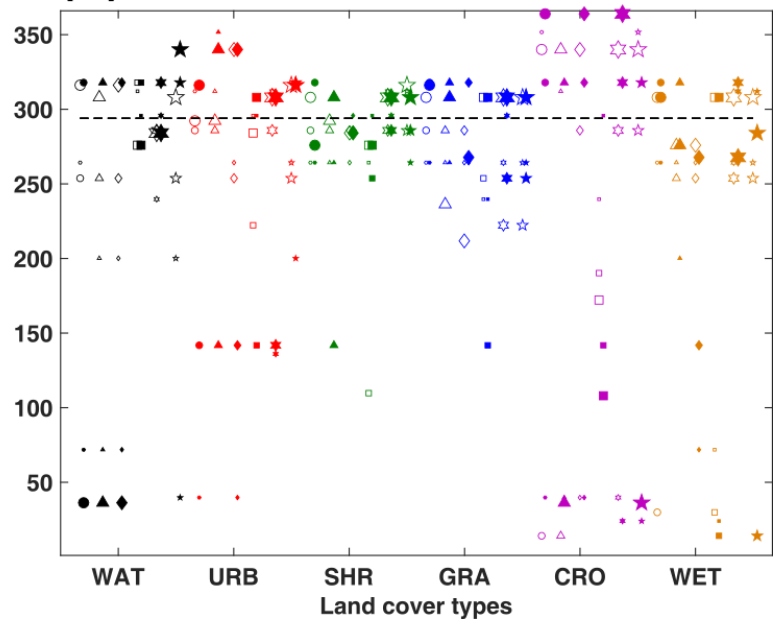

Figure 5. Distribution of the day of year (DOY) for maximum $\mathrm{R}^{2}$ (not filled marker) and minimum RMSE (filled marker) value for year 2001, 2003 and 2008. The corresponding simulation date (dash line) is (a) 14 January (DOY: 14), (b) 12 April (DOY: 102), (c) 9 July (DOY: 190) and (d) 21 October (DOY: 294) for year 2009, respectively. The size of marker from small to big denotes years 2001, 2003 and 2008, respectively. The markers for six Landsat-like bands are circle, triangle, diamond, square, hexagram and pentagram, respectively. The color for each land cover type is black (WAT: water), red (URB: urban), green (SHR: shrub), blue (GRA, grassland), violet (CRO: cropland) and brown (WET: wetland). The meaning of marker and color for symbols is the same for Figure 6.

When the simulation date was 12 April 2009 (DOY: 102), the $\mathrm{R}^{2}$ and RMSE value varied with the increasing of $T_{b s}$, and the overall trend of the accuracy was flat compared to the simulation date of 14 January 2009. The high $\mathrm{R}^{2}$ values often occurred in the middle of the year (Figure 5b). Two peaks of $\mathrm{R}^{2}$ existed for six land cover types except simulated reflectance of band 4 for cropland and wetland. 
Meanwhile, the magnitude of RMSE was lower at the middle of the year (Figures S15 and S16). For cropland, no $\mathrm{R}^{2}$ value exceeded 0.60 for each band, and RMSE value was slightly higher than the result of first simulation date, 14 January 2009 (Figures S15a and S16a). The trend of $\mathrm{R}^{2}$ for six land cover types was similar compared to the first simulation date.

When the simulation date was 9 July 2009 (DOY: 190), the result pattern ( $\mathrm{R}^{2}$, RMSE) was similar to second simulation date, 12 April 2009 (Figures 5c, S17 and S18). Combining the $\mathrm{R}^{2}$ and RMSE, the accuracy of simulated reflectance of cropland was lower than the second simulation date (Figures S17a and S18a). The RMSE of band 4, 5, and 7 for water was still higher than the first three bands (Figure S18e).

(a)

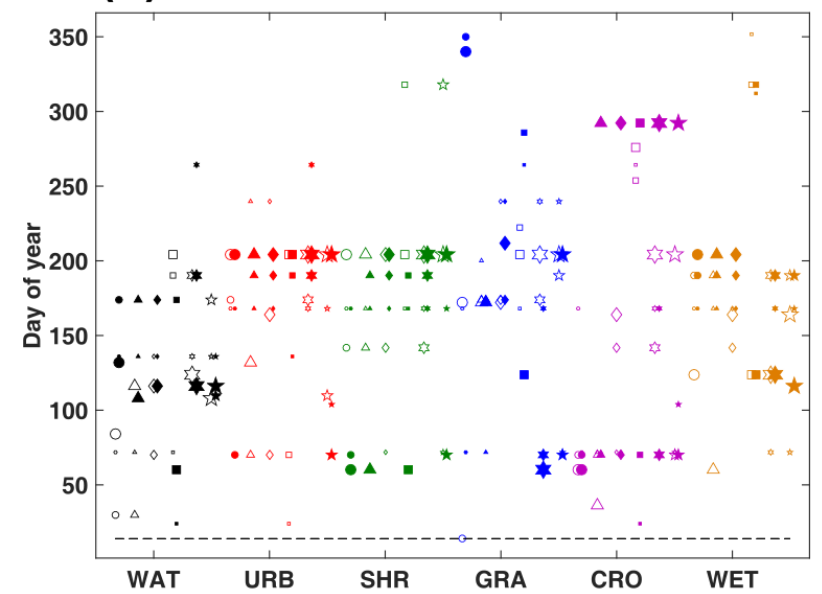

(c)

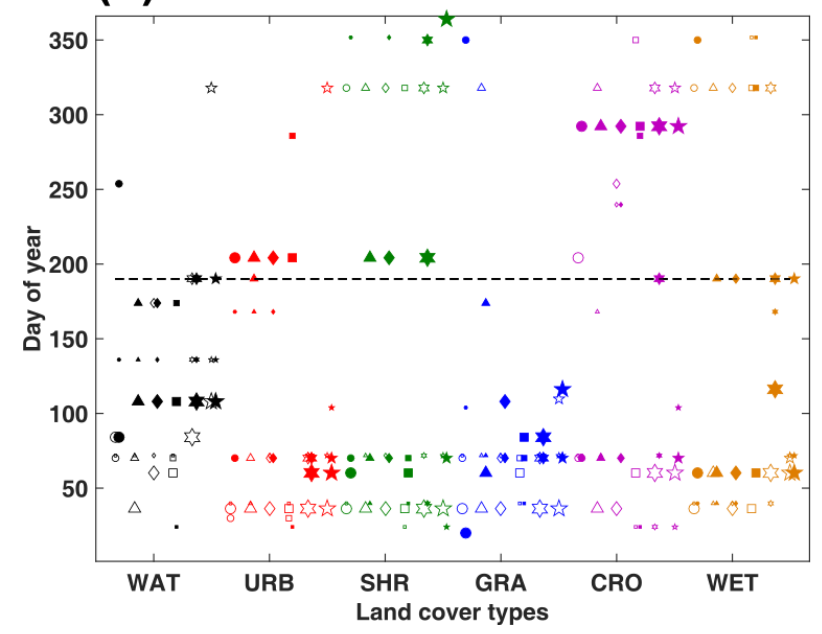

(b)

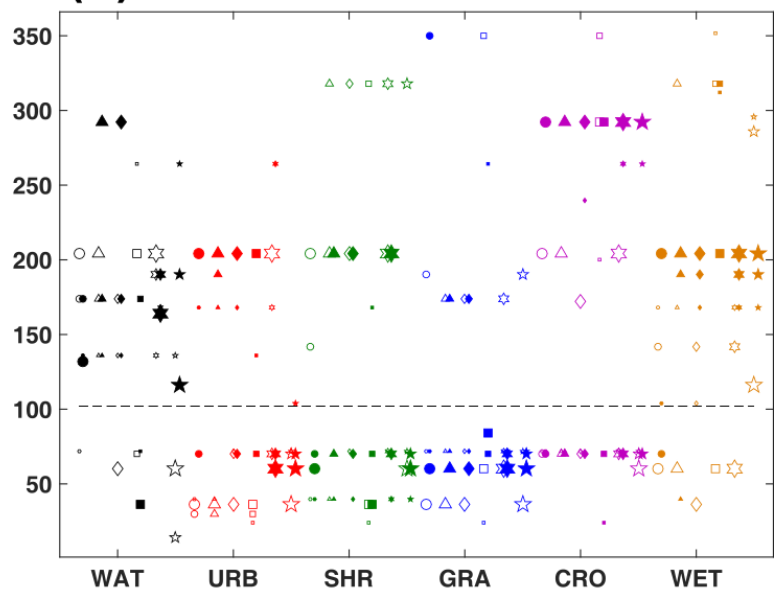

(d)

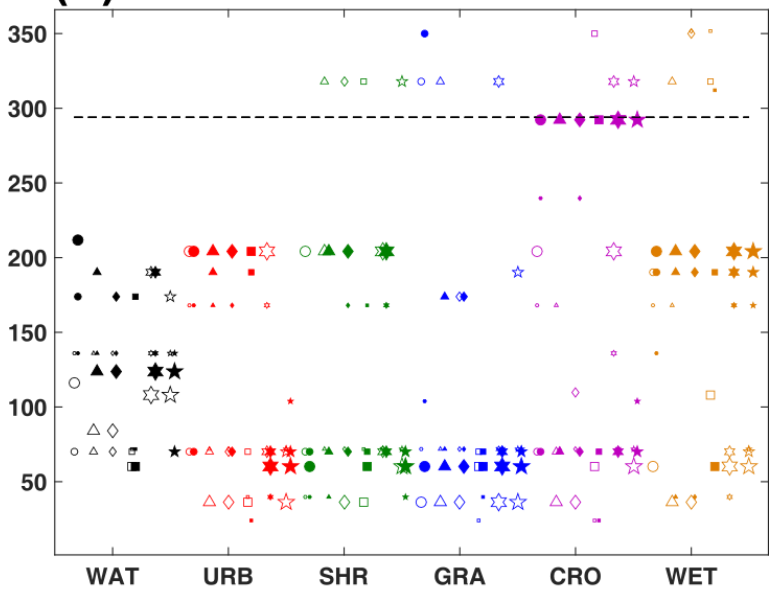

Figure 6. Distribution of the day of year (DOY) for minimum $\mathrm{R}^{2}$ (not filled marker) and maximum RMSE (filled marker) value for year 2001, 2003 and 2008. The corresponding simulation date (dash line) is (a) 14 January (DOY: 14), (b) 12 April (DOY: 102), (c) 9 July (DOY: 190) and (d) 21 October (DOY: 294) for year 2009, respectively. The size of marker from small to big denotes year 2001, 2003 and 2008 respectively.

When the simulation date was set as 21 October 2009 (DOY: 294), the $\mathrm{R}^{2}$ at the near side of the simulation date had higher value (Figure 5d). The magnitude of RMSE was also similar to the other simulation date (Figures S19 and S20). However, the shape of $\mathrm{R}^{2}$ value was different to the first 
simulation date. In the other words, the high value of $\mathrm{R}^{2}$ occurred at the edge of the year for the first simulation date (14 January 2009), but the high $\mathrm{R}^{2}$ value occurred at the near side of the simulation date for the last simulation date (21 October 2009).

\section{Discussion}

For the six land cover types within the study area, the performance of STARFM was evaluated by two ways, one was a fixed base date and the other was a fixed simulation date.

Four base dates (9 February, 16 May, 28 August and 8 November 2001) were selected from the total 44 base dates, and were assumed to represent the average status of winter, spring, summer and autumn. The selection of different base dates affected the accuracy of the simulated reflectance. This phenomenon was also observed in the results using a specific simulation date. The high $\mathrm{R}^{2}$ and corresponding low RMSE value was often located at the same season. For the $\mathrm{R}^{2}$ value in the same season (base or other year), the longer the temporal distance was, the lower $\mathrm{R}^{2}$ value obtained. Meanwhile, the $\mathrm{R}^{2}$ value at the same season of other year might be higher than at the different season of the same year. The reason for high $\mathrm{R}^{2}$ value is the similar vegetation phenology or land surface status between the base and simulation date [26,27]. For example, high $\mathrm{R}^{2}$ value always occurred near the beginning or end of the simulation year when the base dates of 9 February 2001 (Figure 7) and 8 November 2001 (Figure 3) were selected. A high $\mathrm{R}^{2}$ and low RMSE value always occurred in the middle of the simulation year when the base dates of 16 May 2001 and 28 August 2001 were selected (Figure 3). For the results obtained using a specific simulation date, a similar status was also found (Figure 5). This may indicate that a good result of STARFM can be obtained in the situations when the base and simulation dates are in the same season. However, the temporal distance from base/simulation date is varied for different land cover types.
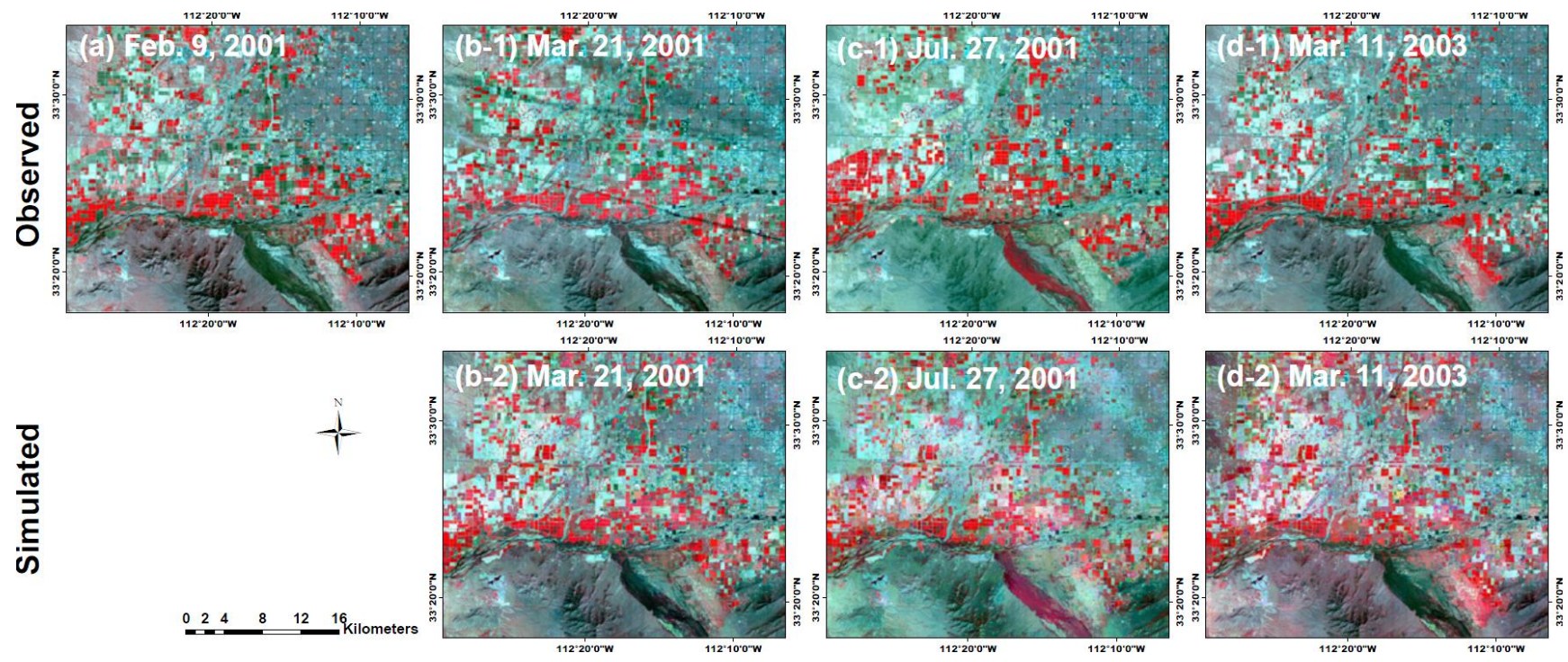

Figure 7. Visual comparison between the observed and simulated Landsat reflectance (Near-infrared (NIR)-red-green composite) using the base Landsat-MODIS pair data at 9 February 2001. The upper/lower row is the observed/simulated Landsat reflectance. 
Table 2. Percentage (\%) of land cover change for the three periods. The abbreviations CRO, GRA, SHR, URB, WAT, WET and OTH denote cropland, grassland, shrub, urban, water, wetland and others, respectively. The subscripts 'from' and 'to' denote the original and latest land cover type, respectively.

\begin{tabular}{|c|c|c|c|c|c|c|c|c|c|}
\hline & & CROto & GRAto $_{\text {to }}$ & SHRto $_{\text {to }}$ & $\mathbf{U R B}_{\text {to }}$ & WAT $_{\text {to }}$ & WET $_{\text {to }}$ & OTH $_{\text {to }}$ & Total $_{\text {to }}$ \\
\hline \multirow{8}{*}{$\begin{array}{c}2001 \\
\rightarrow 2006\end{array}$} & $\mathrm{CRO}_{\text {from }}$ & 25.79 & - & 0.73 & 4.08 & 0.04 & 0.00 & - & 30.65 \\
\hline & $\mathrm{GRA}_{\text {from }}$ & - & 0.82 & 0.02 & 0.05 & 0.01 & 0.00 & - & 0.90 \\
\hline & SHR $_{\text {from }}$ & 0.09 & - & 33.09 & 2.03 & 0.06 & - & - & 35.27 \\
\hline & $\mathrm{URB}_{\text {from }}$ & - & - & 0.00 & 28.97 & - & - & - & 28.97 \\
\hline & $\mathrm{WAT}_{\text {from }}$ & - & - & 0.00 & 0.01 & 0.31 & 0.01 & - & 0.33 \\
\hline & $\mathrm{WET}_{\text {from }}$ & - & - & 0.06 & 0.05 & 0.01 & 3.69 & - & 3.81 \\
\hline & $\mathrm{OTH}_{\text {from }}$ & 0.00 & - & & 0.00 & - & 0.07 & - & 0.08 \\
\hline & Total $_{\text {from }}$ & 25.88 & 0.82 & 33.91 & 35.19 & 0.43 & 3.77 & 0.00 & 100.00 \\
\hline \multirow{8}{*}{$\begin{array}{c}2006 \\
\rightarrow 2011\end{array}$} & $\mathrm{CRO}_{\text {from }}$ & 21.77 & - & 0.03 & 4.00 & 0.09 & - & - & 25.88 \\
\hline & $\mathrm{GRA}_{\text {from }}$ & - & 0.77 & 0.02 & 0.01 & 0.01 & 0.00 & - & 0.81 \\
\hline & $\mathrm{SHR}_{\text {from }}$ & - & - & 32.35 & 1.53 & 0.03 & - & - & 33.91 \\
\hline & $\mathrm{URB}_{\text {from }}$ & - & - & - & 35.19 & 0.00 & - & - & 35.19 \\
\hline & $\mathrm{WAT}_{\text {from }}$ & - & - & 0.01 & 0.00 & 0.42 & - & - & 0.43 \\
\hline & $\mathrm{WET}_{\text {from }}$ & - & - & - & 0.02 & - & 3.75 & - & 3.77 \\
\hline & $\mathrm{OTH}_{\text {from }}$ & - & - & - & - & - & - & - & 0.00 \\
\hline & Total $_{\text {from }}$ & 21.77 & 0.77 & 32.40 & 40.75 & 0.55 & 3.75 & 0.00 & 100.00 \\
\hline \multirow{8}{*}{$\begin{array}{c}2001 \\
\rightarrow 2011\end{array}$} & $\mathrm{CRO}_{\text {from }}$ & 21.68 & - & 0.66 & 8.17 & 0.13 & 0.00 & - & 30.65 \\
\hline & $\mathrm{GRA}_{\text {from }}$ & 0.00 & 0.77 & 0.04 & 0.07 & 0.02 & 0.00 & - & 0.90 \\
\hline & $\mathrm{SHR}_{\text {from }}$ & 0.08 & - & 31.63 & 3.48 & 0.08 & 0.06 & - & 35.34 \\
\hline & $\mathrm{URB}_{\text {from }}$ & - & - & 0.00 & 28.97 & 0.00 & 0.00 & - & 28.97 \\
\hline & $\mathrm{WAT}_{\text {from }}$ & - & - & 0.00 & 0.01 & 0.30 & 0.01 & - & 0.33 \\
\hline & $\mathrm{WET}_{\text {from }}$ & - & - & 0.06 & 0.06 & 0.01 & 3.67 & - & 3.81 \\
\hline & $\mathrm{OTH}_{\text {from }}$ & 0.00 & - & - & 0.00 & - & - & 0.00 & 0.01 \\
\hline & Total $_{\text {from }}$ & 21.77 & 0.77 & 32.40 & 40.75 & 0.55 & 3.75 & 0.00 & 100.00 \\
\hline
\end{tabular}

More detailed information was obtained by combining the land cover types within the study area (Table 2, Figure 8). For cropland, the overall $\mathrm{R}^{2}$ values of the six Landsat bands for four base dates were low, especially for band 4 (near-infrared band). The reason for the low accuracy for simulated reflectance could be attributed to the rapid variation of the cropland canopy structure, especially during the growing season. For the base date of 9 February 2001, the accuracy of simulated reflectance is quite low, the maximum $\mathrm{R}^{2}$ value is 0.50 for band 3; possibly, the reflectance of winter is essentially different compared to other seasons, which lead to the lower $\mathrm{R}^{2}$ value. For a specific simulation date, when the base date was similar to the first simulation date (14 January 2009), the $\mathrm{R}^{2}$ value can exceeded 0.6, whereas the $\mathrm{R}^{2}$ value of the six Landsat bands was lower than 0.6 using other three simulation dates. It is possible that the crops had not been planted yet, and most of this area therefore had no vegetation. The surface ground status would then be almost identical between the base and simulation dates. It can also been reflected from the DOY distribution of lowest $\mathrm{R}^{2}$ and highest RMSE value of each year (Figures 4 and 6). The land cover change of the cropland is another reason for the low accuracy of the simulated reflectance, with $4.08 \%, 4 \%$ and $8.17 \%$ of the total study area for cropland area converted to urban area 
from 2001 to 2006, 2006 to 2011, and 2001 to 2011, respectively. The percentage of overall change for the combination of all three periods was lower than the sum of the separate periods because some change occurred twice in the same pixel. In this case, the most recent land cover class was used [20]. Grassland appears invariant compared to cropland and urban areas. However, the area of grassland is small, the representativeness of the result is limited, and needs to be improved. For urban areas, there are two significant decreases in the $\mathrm{R}^{2}$ value at beginning of 2004 and 2009. The reason for this phenomenon is the assumption of representativeness of the NLCD 2001, 2006, and 2011. The spatial distribution of urban area for year 2001-2003, 2004-2008, and 2009-2012 can be represented by NLCD 2001, NLCD 2006 and NLCD 2011, respectively. With the development of the city within the study area, the urban area is expanded. Consequently, the $\mathrm{R}^{2}$ value for the periods of 2004-2008 and 2009-2012 can be improved when the base date is set within these two periods, respectively. For shrub, the $\mathrm{R}^{2}$ value had an obvious seasonal variation, and remained at a good level. Perhaps the canopy structure for shrub is stable, and this leads to good result of simulated surface reflectance compared to other land cover types. For water, because the reflectivity of water is small, the overall $\mathrm{R}^{2}$ values of the six Landsat bands were not good. The $\mathrm{R}^{2}$ value, which was higher than 0.6 , could only be obtained when the simulation date is near to the base date. For wetland, the accuracy of simulated reflectance for band 4 was worse than other bands (Figures S2f, S5f, S9f, and S11f), which might be because wetland contains water surface, and the reflectivity was low. A significant decrease in the $\mathrm{R}^{2}$ was apparent at the beginning of 2009; possibly, the land cover type of wetland had changed, whereas it is not reflected using NLCD 2011.

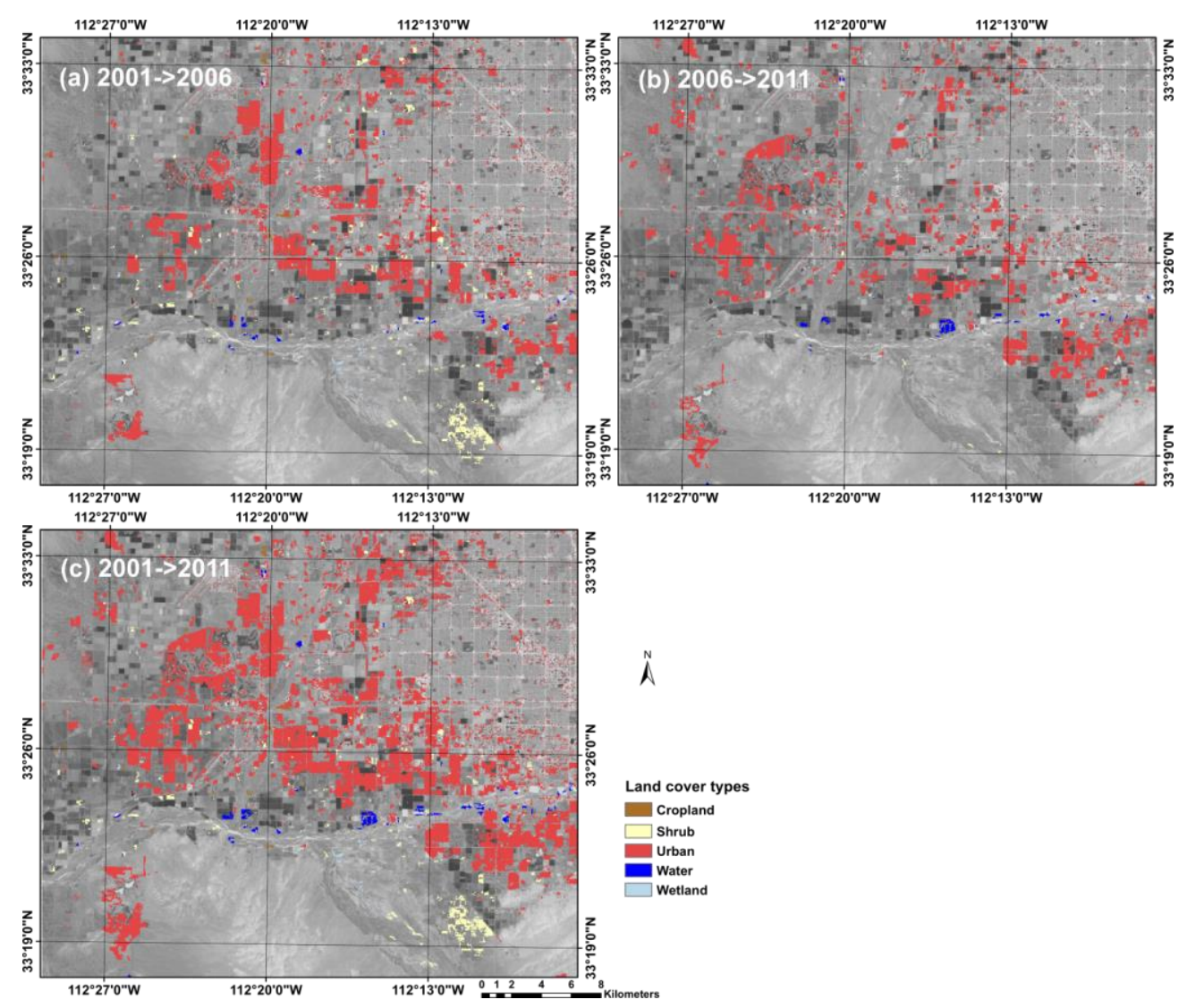

Figure 8. Spatial distribution of land cover changes for the study area for (a) 2001 to 2006, (b) 2006 to 2011, and (c) 2001 to 2011. The base map is band 4 (near-infrared band) of Landsat data on 8 May 2001. The land cover shown on the map is the latest land cover type. 
There are several limitations and constraints for this study. First, the STARFM cannot accurately simulate the short term, transient changes that are not recorded in either base date or simulation date $[3,12]$. Second, the use of eight-day surface reflectance from the MODIS product (MOD09A1) may affect the accuracy of simulated surface reflectance. The phenology of vegetation or other associated factors may change within the eight-day period. Meanwhile, Bidirectional Reflectance Distribution Function (BRDF) effect of MODIS eight-day surface reflectance may also have some influence of the simulated result. Third, the performance of STARFM will be affected if the land cover type of the study area had changed from base date to simulation date. Last, the sensor degradation is not considered for the study, which may affect the accuracy of result with long temporal interval. Therefore, further studies should focus on the following issues to improve the accuracy of the simulated results: (i) the usage of improved versions based on STARFM, and (ii) a combination of data assimilation and STARFM.

\section{Conclusion}

The performance of the spatial-temporal image fusion model (STARFM) was assessed for temporal interval of different sizes using Landsat and MODIS images from the southwest of the continental United States. Two schemes were applied for the evaluation, one using a fixed base date and the other using a specific simulation date. In addition, the land cover data at three periods (2001, 2006 and 2011) were used in the study. The accuracy of simulated reflectance for six Landsat bands was assessed for each of the six land cover types. Although it is expected that the accuracy will reduce with the increased interval from the base date, this study provides a thorough discussion of possible reasons affecting the accuracy of the simulated data and warns readers about limitations of the study.

Generally, there was an obvious seasonal variation for simulated reflectance for each land cover type. To obtain the simulated reflectance at a particular date, the selection of nearer base date during the same season or the same season from a different year will produce results with higher accuracy compared to the rest of the dates. However, the corresponding $T_{b s}$ value for higher accuracy is different for different land cover types. According to the result of the study area, the land cover with most variation is cropland, which need data with the nearest date (especially at growing season) during the same year to obtain a simulated reflectance with high accuracy. For a land cover type with a stable structure, such as urban, shrub and grassland, the $T_{b s}$ value can be more than 100 days, especially during the growing season. For water and wetland, the $T_{b s}$ value is varied, and the performance of STARFM needs to be improved for these land cover types. The results provided guidance on how to select an appropriate temporal interval for specific applications when using the STARFM method.

\section{Acknowledgments}

This research is supported by the research grant funded by Natural Science Foundation of China (grant No. 41371362), the research grant funded by China Postdoctoral Science Foundation (grant No. 2014M550871), the research grant of the Direct Youth Foundation in Institute of Remote Sensing and Digital Earth, Chinese Academy of Sciences (grant No. Y5SJ2000CX), Major Special Project - the China High-Resolution Earth Observation System. We thank the USGS Earth Resources Observation Systems (EROS) data center for providing Landsat data and the Land Processes Distributed Active Archive Center (LP-DAAC) and MODIS science team for providing free MODIS products. 


\section{Author Contributions}

Dongjie Fu, Lifu Zhang and Hao Chen conceived and designed the experiments; Dongjie Fu, Hao Chen and Juan Wang performed the experiments; Dongjie Fu, Xuejian Sun and Taixia Wu analyzed the data; and Dongjie Fu drafted the paper. All authors read and edited drafts, and approved the final manuscript.

\section{Conflicts of Interest}

The authors declare no conflict of interest.

\section{References}

1. Emelyanova, I.V.; McVicar, T.R.; Van Niel, T.G.; Li, L.T.; van Dijk, A.I.J.M. Assessing the accuracy of blending Landsat-MODIS surface reflectances in two landscapes with contrasting spatial and temporal dynamics: A framework for algorithm selection. Remote Sens. Environ. 2013, 133, 193-209.

2. Gevaert, C.M.; García-Haro, F.J. A comparison of STARFM and an unmixing-based algorithm for Landsat and MODIS data fusion. Remote Sens. Environ. 2015, 156, 34-44.

3. Gao, F.; Masek, J.; Schwaller, M.; Hall, F. On the blending of the Landsat and MODIS surface reflectance: Predicting daily Landsat surface reflectance. IEEE Trans. Geosci Remote Sens. 2006, 44, 2207-2218.

4. Hilker, T.; Wulder, M.A.; Coops, N.C.; Linke, J.; McDermid, G.; Masek, J.G.; Gao, F.; White, J.C. A new data fusion model for high spatial- and temporal-resolution mapping of forest disturbance based on Landsat and MODIS. Remote Sens. Environ. 2009, 113, 1613-1627.

5. Cammalleri, C.; Anderson, M.C.; Gao, F.; Hain, C.R.; Kustas, W.P. Mapping daily evapotranspiration at field scales over rainfed and irrigated agricultural areas using remote sensing data fusion. Agric. For. Meteorol. 2014, 186, 1-11.

6. Fu, D.; Chen, B.; Zhang, H.; Wang, J.; Black, T.A.; Amiro, B.D.; Bohrer, G.; Bolstad, P.; Coulter, R.; Rahman, A.F.; et al. Estimating landscape net ecosystem exchange at high spatial-temporal resolution based on Landsat data, an improved upscaling model framework, and eddy covariance flux measurements. Remote Sens. Environ. 2014, 141, 90-104.

7. Singh, D. Generation and evaluation of gross primary productivity using Landsat data through blending with MODIS data. Int. J. Appl. Earth Obs. Geoinform. 2011, 13, 59-69.

8. Watts, J.D.; Powell, S.L.; Lawrence, R.L.; Hilker, T. Improved classification of conservation tillage adoption using high temporal and synthetic satellite imagery. Remote Sens. Environ. 2011, 115, 66-75.

9. Walker, J.J.; de Beurs, K.M.; Wynne, R.H.; Gao, F. Evaluation of Landsat and MODIS data fusion products for analysis of dryland forest phenology. Remote Sens. Environ. 2012, 117, 381-393.

10. Wu, M.; Wu, C.; Huang, W.; Niu, Z.; Wang, C. High-resolution leaf area index estimation from synthetic Landsat data generated by a spatial and temporal data fusion model. Comput. Electron. Agric. 2015, 115, 1-11. 
11. Liu, H.; Weng, Q.H. Enhancing temporal resolution of satellite imagery for public health studies: A case study of West Nile Virus outbreak in Los Angeles in 2007. Remote Sens. Environ. 2012, $117,57-71$.

12. Zhu, X.L.; Chen, J.; Gao, F.; Chen, X.H.; Masek, J.G. An enhanced spatial and temporal adaptive reflectance fusion model for complex heterogeneous regions. Remote Sens. Environ. 2010, 114, 2610-2623.

13. Fu, D.; Chen, B.; Wang, J.; Zhu, X.; Hilker, T. An improved image fusion approach based on enhanced spatial and temporal the adaptive reflectance fusion model. Remote Sens. 2013, 5, 6346-6360.

14. Huang, B.; Wang, J.; Song, H.; Fu, D.; Wong, K. Generating high spatiotemporal resolution land surface temperature for urban heat island monitoring. IEEE Geosci. Remote Sens. Lett. 2013, 10, 1011-1015.

15. Weng, Q.; Fu, P.; Gao, F. Generating daily land surface temperature at Landsat resolution by fusing Landsat and MODIS data. Remote Sens. Environ. 2014, 145, 55-67.

16. Gao, F.; Hilker, T.; Zhu, X.; Anderson, M.; Masek, J.; Wang, P.; Yang, Y. Fusing Landsat and MODIS data for vegetation monitoring. IEEE Geosci. Remote Sens. Mag. 2015, 3, 47-60.

17. Grimm, N.; Redman, C. Approaches to the study of urban ecosystems: The case of Central Arizona-Phoenix. Urban. Ecosyst. 2004, 7, 199-213.

18. Buyantuyev, A.; Wu, J. Urbanization alters spatiotemporal patterns of ecosystem primary production: A case study of the Phoenix metropolitan region, USA. J. Arid Environ. 2009, 73, 512-520.

19. Buyantuyev, A.; Wu, J.; Gries, C. Estimating vegetation cover in an urban environment based on landsat ETM+ imagery: A case study in Phoenix, USA. Int. J. Remote Sens. 2007, 28, 269-291.

20. Jin, S.; Yang, L.; Danielson, P.; Homer, C.; Fry, J.; Xian, G. A comprehensive change detection method for updating the national Land Cover Database to circa 2011. Remote Sens. Environ. 2013, 132, 159-175.

21. Fry, J.A.; Xian, G.; Jin, S.; Dewitz, J.A.; Homer, C.G.; LIMIN, Y.; Barnes, C.A.; Herold, N.D.; Wickham, J.D. Completion of the 2006 National Land Cover Database for the conterminous United States. Photogramm. Eng. Remote Sens. 2011, 77, 858-864.

22. Homer, C.; Dewitz, J.; Fry, J.; Coan, M.; Hossain, N.; Larson, C.; Herold, N.; McKerrow, A.; VanDriel, J.N.; Wickham, J. Completion of the 2001 National Land Cover Database for the counterminous United States. Photogramm. Eng. Remote Sens. 2007, 73, 337-341.

23. Buyantuyev, A.; Wu, J. Urbanization diversifies land surface phenology in arid environments: Interactions among vegetation, climatic variation, and land use pattern in the Phoenix metropolitan region, USA. Landsc. Urban Plan. 2012, 105, 149-159.

24. Wickham, J.D.; Stehman, S.V.; Gass, L.; Dewitz, J.; Fry, J.A.; Wade, T.G. Accuracy assessment of NLCD 2006 land cover and impervious surface. Remote Sens. Environ. 2013, 130, 294-304.

25. Wickham, J.; Homer, C.; Vogelmann, J.; McKerrow, A.; Mueller, R.; Herold, N.; Coulston, J. The multi-resolution land characteristics (MRLC) consortium-20 years of development and integration of USA national land cover data. Remote Sens. 2014, 6, 7424-7441.

26. Sexton, J.O.; Urban, D.L.; Donohue, M.J.; Song, C. Long-term land cover dynamics by multi-temporal classification across the Landsat-5 record. Remote Sens. Environ. 2013, 128, 246-258. 
27. Bhandari, S.; Phinn, S.; Gill, T. Preparing Landsat image time series (LITS) for monitoring changes in vegetation phenology in Queensland, Australia. Remote Sens. 2012, 4, 1856-1886.

(C) 2015 by the authors; licensee MDPI, Basel, Switzerland. This article is an open access article distributed under the terms and conditions of the Creative Commons Attribution license (http://creativecommons.org/licenses/by/4.0/). 